\title{
Campylobacteriosis in New Zealand: results of a case-control study
}

Jason Eberhart-Phillips, Natalie Walker, Nicholas Garrett, Derek Bell, David Sinclair, William Rainger, Michael Bates

\begin{abstract}
Study objective-To identify and assess the contributions of major risk factors for campylobacteriosis in New Zealand.

Design-Case-control study. Home interviews were conducted over nine months using a standardised questionnaire to assess recent food consumption and other exposures.

Setting-Four centres in New Zealand with high notification rates of campylobacter infections-Auckland, Hamilton, Wellington, and Christchurch.

Participants-Case patients were 621 people notified between 1 June 1994 and 28 February 1995 as having campylobacter infection. Control subjects were selected randomly from telephone directories, and were matched $1: 1$ with case patients in relation to sex, age group, and home telephone prefix.

Results-Risk of campylobacteriosis was strongly associated with recent consumption of raw or undercooked chicken (matched odds ratio $4.52,95 \%$ confidence interval $2.88,7.10$ ). There was also an increased risk with chicken eaten in restaurants (matched odds ratio 3.85; $2.52,5.88)$. Recent consumption of baked or roasted chicken seemed to be protective. Campylobacteriosis was also associated with recent overseas travel, rainwater as a source of water at home, consumption of raw dairy products, and contact with puppies and cattle, particularly calves.

Conclusions-Improperly cooked chicken seems to be associated with a large proportion of campylobacteriosis in New Zealand. Thorough cooking of chicken in homes and restaurants could reduce considerably the incidence of this disease.
\end{abstract}

(F Epidemiol Community Health 1997;51:686-691)

Campylobacteriosis is by far the most frequently notified communicable disease in New Zealand. In 1995, there were 7525 notifications, which corresponds to a rate of more than 223 reported cases per 100000 population. $^{1}$

Notifications have increased steadily from 1980 , the year that campylobacter infections became reportable in New Zealand. Since the start of 1992, campylobacter infections have accounted for approximately two thirds of all notifiable disease reports. New Zealand's recent notification rates for campylobacteriosis have been twice those of England and three times those reported from Australia and Canada. ${ }^{2}$ Most cases occur in children and young adults. Nearly all cases are sporadic, and they tend to occur in the spring and summer months.

Although rarely fatal, campylobacter infections cause considerable morbidity and time lost from work and school. Infection occasionally results in serious sequelae, including reactive arthritis and Guillain-Barré syndrome. Direct costs for reported cases of campylobacteriosis in New Zealand have been estimated at NZ $\$ 4.2$ million per year. ${ }^{4}$

The causes of New Zealand's high incidence rates are unknown. A study of 100 cases and controls from Christchurch in 1992-93 found that eating undercooked chicken was associated with campylobacteriosis (odds ratio = $4.94,95 \%$ confidence interval ( $95 \% \mathrm{CI}) 1.03$, 23.62). ${ }^{5}$

Case-control studies in other developed countries have linked campylobacteriosis repeatedly with consumption of poultry. ${ }^{6-9}$ Other factors with strong associations have included consumption of untreated water, ${ }^{9}$ consumption of raw milk, ${ }^{9-11}$ contact with cats, ${ }^{69}$ contact with puppies, ${ }^{12}$ contact with animals having diarrhoea, ${ }^{13}$ poor cleaning of chopping boards, ${ }^{8}$ travel to a developing country, ${ }^{14}$ and consumption of milk from bottles pecked at by birds. ${ }^{15}$

The multi-centre analysis of gastroenteritis induced by campylobacter (MAGIC) was designed to examine a wide array of hypotheses about how New Zealanders are becoming infected with this organism. With its large and representative study population, the MAGIC study was designed to have the statistical power to detect all major risk factors for this disease in New Zealand.

\section{Methods}

The study had a case-control design. Data were collected between 1 June 1994 and 28 February 1995 through home interviews using a standardised questionnaire. Subjects resided in the four urban centres of Auckland, Hamilton, Wellington, and Christchurch (or in the surrounding rural areas). These regions have had some of New Zealand's highest rates of campylobacter notifications in recent years, and ethics committees based in each of the four regions approved the study.

Cases were identified through routine notifications to medical officers of health by medical practitioners. Nearly all notifications of campylobacter infection in New Zealand are 
Table 1 Characteristics of cases and controls

\begin{tabular}{lcc}
\hline Characteristics & Cases No (\%) & $\begin{array}{l}\text { Controls No } \\
(\%)\end{array}$ \\
\hline Ethnicity: & & \\
$\quad$ European & $564(90.8)$ & $563(90.7)$ \\
Maori & $33(5.3)$ & $33(5.3)$ \\
Pacific Island & $5(0.8)$ & $7(1.1)$ \\
Asian & $11(1.8)$ & $4(0.6)$ \\
Indian & $5(0.8)$ & $10(1.6)$ \\
Other & $3(0.5)$ & $4(0.6)$ \\
Household income (NZ \$ / y): & $28(4.8)$ & $33(5.6)$ \\
<10 000 & $103(17.5)$ & $106(17.9)$ \\
10-25 000 & $161(27.4)$ & $155(26.1)$ \\
25-40 000 & $296(50.3)$ & $299(50.4)$ \\
$>40$ 000 & & \\
Highest school qualification: & $90(15.5)$ & $88(15.0)$ \\
No qualification & $109(18.7)$ & $105(17.9)$ \\
School certificate $\geqslant 1$ subject & $144(24.7)$ & $151(25.7)$ \\
Sixth form certificate or university entrance in $\geqslant 1$ subject & $232(39.9)$ & $237(40.4)$ \\
University degree or technical qualification & $7(1.2)$ & $6(1.0)$ \\
Other qualification & & \\
Urban $v$ rural residence: & $532(85.7)$ & $541(87.1)$ \\
Urban & $89(14.3)$ & $80(12.9)$ \\
Rural & & \\
\hline
\end{tabular}

confirmed in the laboratory. At the start of the study general practitioners serving the four regions were reminded to report all cases of campylobacteriosis in a timely manner. Enhanced reporting was prompted by letters to the GPs from the local study coordinators, by publicity about the study in medical newspapers, and by reminders to GPs from laboratories that were identifying the organism in their patients.

All case patients whose illness was notified within 14 days of onset were eligible, with the following exceptions: persons who did not speak English well, those who did not have home telephones, and those who were living in an institution. Cases from recognised outbreaks were not included. For household clusters, only the first reported case patient was eligible. In months when the number of notifications exceeded the target sample size for a centre, a systematic random sampling method was used by the local study coordinators to select subjects to approach for inclusion in the study.

Case patients were approached by telephone in a standardised manner. All who agreed to participate were interviewed at home within 48 hours of the time of notification. For eligible case patients under age 16 years, a parent or guardian was interviewed.

Controls were matched to case patients by sex, age group, and home telephone prefix. Matching individuals were located by telephone using residential listings selected in a random fashion from local telephone directories. Repeated attempts were made to contact potential controls who could not be reached on the first approach. No records were kept of the number of calls made to recruit controls. Exclusion criteria for controls were identical to those for case patients, except that potential controls were also excluded if they had reported any diarrhoea in the previous month. Interviews with controls took place within 14 days of the case-patient interview.

The questionnaire examined the subject's food preferences in a typical month, recent exposures to particular foods, and usual food preparation methods. There were also ques-
KEY POINTS

- Campylobacteriosis accounts for approximately two thirds of all notifiable disease reports in New Zealand.

- Recent consumption of raw or undercooked chicken was strongly associated with campylobacteriosis.

- Thorough cooking of chicken could reduce the incidence of campylobacteriosis.

tions on non-food exposures, such as recent travel, home water supply, home sewerage, pet ownership, and occupational exposure to animals.

Data from the questionnaires were doubleentered, and a conditional logistic regression for 1:1 matched data was performed. Exposure variables were expressed in dichotomous categories so that matched odds ratios and $95 \%$ CI could be calculated.

Stepwise logistic regression was then undertaken to identify the combination of variables that best explained the differences between cases and controls. This method provided odds ratios and $95 \%$ CI for each risk factor independently, adjusting for all other variables included in the model. Following multivariate analysis, population attributable risk percentages were computed, given a reference population with the same distribution of age, sex, and telephone prefix as the participants in this study. These were calculated to assess the relative contribution of each independent risk factor to the incidence of disease.

\section{Results}

There were 621 case patients and an equal number of matched controls recruited into the study. The case patients represented $24 \%$ of the 2585 persons notified with campylobacter infections in the four centres during the nine months of data collection. There were 186 potential case patients $(8 \%)$ who could not be located within 48 hours of notification, 77 (3\%) who refused to participate, 58 (2\%) who had to be excluded after interview because a matching control could not be found within 14 days, and $14(0.5 \%)$ who met the other exclusion criteria. The remaining 1629 persons notified with campylobacteriosis were not sought for interview because their illness was part of a recognised outbreak ( $1 \%)$, because their notification was more than 14 days after the onset of illness ( $9 \%$ ), or because they were

Table 2 Frequency of symptoms reported by cases

\begin{tabular}{ll}
\hline Symptoms & No (\%) \\
\hline Diarrhoea & $612(98.6)$ \\
Stomach pains/cramps & $558(89.9)$ \\
Fever & $454(73.1)$ \\
Nausea & $394(63.4)$ \\
Blood in stool & $219(35.3)$ \\
Vomiting & $194(31.3)$ \\
Headache & $152(24.5)$ \\
Lethargic/tired & $94(15.1)$ \\
Body aches and pains & $68(11.0)$ \\
\hline
\end{tabular}


Table 3 Odds ratios for food exposures in prior 10 days, matched by age, sex, and telephone prefix

\begin{tabular}{|c|c|c|c|}
\hline Food consumed in prior $10 \mathrm{~d}$ & $\begin{array}{l}\text { Cases } \\
\text { No (\%) }\end{array}$ & $\begin{array}{l}\text { Controls } \\
\text { No }(\%)\end{array}$ & Odds ratio $(95 \% \mathrm{CI})$ \\
\hline More than one poultry meal & $401(64.6)$ & $364(58.6)$ & $1.31(1.03,1.67)$ \\
\hline More than one chicken meal & $398(64.1)$ & $361(58.1)$ & $1.31(1.03,1.66)$ \\
\hline Any chicken raw or undercooked & $108(17.4)$ & $27(4.3)$ & $4.52(2.88,7.10)$ \\
\hline \multicolumn{4}{|l|}{ Cooking method: } \\
\hline Any barbecued chicken & $68(11.0)$ & $30(4.8)$ & $2.60(1.64,4.12)$ \\
\hline Any fried chicken & $192(30.9)$ & $141(22.7)$ & $1.55(1.19,2.01)$ \\
\hline Any baked/roasted chicken & $265(42.7)$ & $308(49.6)$ & $0.75(0.60,0.94)$ \\
\hline \multicolumn{4}{|l|}{ Type of chicken serving: } \\
\hline Any whole chicken & $196(31.6)$ & $271(43.6)$ & $0.59(0.46,0.74)$ \\
\hline Any chicken pieces & $418(67.3)$ & $346(55.7)$ & $1.67(1.32,2.13)$ \\
\hline \multicolumn{4}{|l|}{ Site of preparation: } \\
\hline Any chicken prepared at own home & $387(62.3)$ & $441(71.0)$ & $0.67(0.52,0.85)$ \\
\hline Any chicken prepared at someone else's house & $82(13.2)$ & $49(7.9)$ & $1.75(1.21,2.53)$ \\
\hline Any chicken prepared at a sit-down restaurant & $113(18.2)$ & $36(5.8)$ & $3.85(2.52,5.88)$ \\
\hline Any chicken prepared at a takeaway establishment & $135(21.7)$ & $91(14.7)$ & $1.70(1.24,2.32)$ \\
\hline \multicolumn{4}{|l|}{ Form of purchase: } \\
\hline Any chicken purchased fresh and uncooked, then frozen at home & $118(19.0)$ & $120(19.3)$ & $0.98(0.74,1.30)$ \\
\hline Any chicken purchased fresh and uncooked, and not frozen at home & $120(19.3)$ & $107(17.2)$ & $1.15(0.86,1.54)$ \\
\hline Any chicken purchased frozen & $187(30.1)$ & $260(41.9)$ & $0.61(0.48,0.77)$ \\
\hline Any chicken purchased pre-cooked to take home & $24(3.9)$ & $16(2.6)$ & $1.53(0.80,2.94)$ \\
\hline \multicolumn{4}{|l|}{ Dairy products: } \\
\hline Any unpasteurised milk & $36(5.8)$ & $15(2.4)$ & $3.10(1.52,6.32)$ \\
\hline Any unpasteurised cream & $12(1.9)$ & $1(0.2)$ & $12.00(1.56,92.28)$ \\
\hline
\end{tabular}

not selected in the lottery used when the number of notifications per month exceeded a centre's target sample size (53\%).

Case patients and controls were remarkably similar in terms of ethnicity, household income, highest school qualification, and urban or rural residence, as shown in table 1 . The subjects were also representative of the population reported with campylobacteriosis recently in New Zealand. ${ }^{2}$

Symptoms reported by case patients are shown in table 2. Duration of illness ranged from 1 to 16 days, with a median of 7 days. More than $70 \%$ of case patients sought medical attention for their illness within 3 days of onset.

Table 3 shows matched odds ratios for food exposures in the prior 10 days that were found to be associated with campylobacteriosis. Table 4 shows matched odds ratios for key non-food exposures. No allowance was made for multiple comparisons, and it is likely that some of these associations occurred by chance.
The strongest associations for food exposures were found with recent consumption of chicken, particularly raw or undercooked chicken, or chicken prepared at a sit-down restaurant. Barbecued chicken and fried chicken were positively associated with disease, while consumption of baked or roasted chicken seemed to be protective, as was chicken purchased frozen. Unpasteurised dairy products also were linked strongly with disease.

No special definitions of "raw" or "undercooked" were used. Of the case patients who reported eating raw or undercooked chicken in the previous 10 days, $61 \%$ had eaten such food outside of home, compared with $41 \%$ of controls.

Non-food exposures with strong associations included overseas travel in the prior 10 days, consumption of certain untreated water, and contact with cattle and puppies (particularly handling of their faeces). Occupational contact

Table 4 Odds ratios for non-food exposures, matched by age, sex, and telephone prefix

\begin{tabular}{|c|c|c|c|}
\hline Risk factor & $\begin{array}{l}\text { Cases } \\
\text { No (\%) }\end{array}$ & $\begin{array}{l}\text { Controls } \\
\text { No }(\%)\end{array}$ & Odds ratio $(95 \% \mathrm{CI})$ \\
\hline \multicolumn{4}{|l|}{ Travel: } \\
\hline Overseas travel in prior $10 \mathrm{~d}$ & $31(5.0)$ & $7(1.1)$ & $4.43(1.95,10.06)$ \\
\hline Overseas travel to non-OECD country in prior $10 \mathrm{~d}$ & $16(2.6)$ & $0(0.0)$ & Undefined \\
\hline \multicolumn{4}{|l|}{ Water and sewerage: } \\
\hline Non-city water supply at home & $65(10.5)$ & $61(9.8)$ & $1.15(0.68,1.95)$ \\
\hline Non-city water outside of home in prior $10 \mathrm{~d}$ & $108(17.4)$ & $72(11.6)$ & $1.63(1.17,2.27)$ \\
\hline Rainwater source for home water supply & $23(3.7)$ & $11(1.8)$ & $2.20(1.04,4.65)$ \\
\hline Sewerage problem at home in prior $10 \mathrm{~d}$ & $20(3.2)$ & $7(1.1)$ & $2.86(1.21,6.76)$ \\
\hline \multicolumn{4}{|l|}{ Faeces: } \\
\hline Any handling of animal faeces in prior $10 \mathrm{~d}$ & $139(22.4)$ & $154(24.8)$ & $0.86(0.65,1.14)$ \\
\hline Handling of calf faeces in prior $10 \mathrm{~d}$ & $25(4.0)$ & $7(1.1)$ & $5.50(1.90,15.96)$ \\
\hline Handling of bovine faeces in prior $10 \mathrm{~d}$ & $43(6.9)$ & $20(3.2)$ & $3.09(1.57,6.10)$ \\
\hline Handling of puppy faeces in prior $10 \mathrm{~d}$ & $8(1.3)$ & $1(0.2)$ & $8.00(1.00,63.97)$ \\
\hline \multicolumn{4}{|l|}{ Pets: } \\
\hline Any pets at home & $423(68.1)$ & $437(70.4)$ & $0.89(0.69,1.15)$ \\
\hline Ownership of puppy (dog $<6 \mathrm{mth}$ old) & $26(4.2)$ & $11(1.8)$ & $2.67(1.24,5.74)$ \\
\hline Ownership of two or more puppies & $7(1.1)$ & $0(0.0)$ & Undefined \\
\hline Ownership of caged bird & $65(10.5)$ & $54(8.7)$ & $1.22(0.84,1.79)$ \\
\hline Ownership of three or more caged birds & $14(2.3)$ & $4(0.6)$ & $3.50(1.15,10.63)$ \\
\hline Any pets in home with diarrhoea in prior $10 \mathrm{~d}$ & $25(4.0)$ & $12(1.9)$ & $2.08(1.05,4.15)$ \\
\hline \multicolumn{4}{|l|}{ Other animals: } \\
\hline Any contact with animals in prior $10 \mathrm{~d}$ or at work & $497(80.0)$ & $534(86.0)$ & $0.62(0.44,0.85)$ \\
\hline Any contact with cattle in prior $10 \mathrm{~d}$ or at work & $46(7.4)$ & $24(3.9)$ & $2.29(1.30,4.05)$ \\
\hline Any contact with new/aborted calves in prior $10 \mathrm{~d}$ or at work & $32(5.2)$ & $18(2.9)$ & $2.27(1.12,4.62)$ \\
\hline Occupational contact with any animal carcasses ${ }^{\star}$ & $29(6.4)$ & $15(3.4)$ & $1.92(0.95,3.85)$ \\
\hline Occupational contact with cattle carcasses ${ }^{\star}$ & $20(4.4)$ & $7(1.6)$ & $2.83(1.12,7.19)$ \\
\hline Occupational contact with calf carcasses ${ }^{\star}$ & $10(2.2)$ & $1(0.2)$ & $8.00(1.00,63.97)$ \\
\hline
\end{tabular}

^Denominator excludes children and other persons unable to work. 


\begin{tabular}{|c|c|c|c|}
\hline Risk factor & $\begin{array}{l}\text { Adjusted odds ratio } \\
(95 \% \mathrm{CI})\end{array}$ & $\begin{array}{l}\text { Exposure in } \\
\text { controls (\%) }\end{array}$ & $\begin{array}{l}\text { Population } \\
\text { attributable } \\
\text { risk (\%) }\end{array}$ \\
\hline Rainwater source for home water supply & $3.11(1.30,7.41)$ & 2 & $\star$ \\
\hline Preference for chicken liver $\geqslant 1 / \mathrm{mth}$ & $2.47(1.22,4.98)$ & 3 & * \\
\hline Preference for chicken pieces $\geqslant 1 / \mathrm{wk}$ & $1.44(1.10,1.89)$ & 43 & 16 \\
\hline Puppy ownership & $3.94(1.57,9.88)$ & 2 & 5 \\
\hline \multicolumn{4}{|l|}{ In prior $10 \mathrm{~d}$ : } \\
\hline Any chicken raw or undercooked & $3.71(2.24,6.13)$ & 4 & 11 \\
\hline Any chicken prepared at a sit-down restaurant & $3.53(2.17,5.72)$ & 6 & 13 \\
\hline Any chicken prepared at someone else's house & $1.77(1.12,2.80)$ & 8 & 6 \\
\hline No baked/roasted chicken & $1.75(1.33,2.32)$ & 50 & 27 \\
\hline Any barbecued chicken & $1.88(1.05,3.36)$ & 5 & $\star$ \\
\hline Other raw or undercooked meat or fish & $3.67(2.07,6.50)$ & 5 & 11 \\
\hline Any unpasteurised milk & $3.92(1.66,9.27)$ & 2 & 7 \\
\hline Handling of calf faeces & $4.40(1.34,14.39)$ & 1 & * \\
\hline Sewerage problems at home & $4.35(1.55,12.18)$ & 1 & * \\
\hline
\end{tabular}

$\star$ Population attributable risk $(\%)<5 \%$.

with bovine carcasses was also strongly associated with disease.

Few food preferences in a typical month were associated with disease. Exceptions were a preference for chicken pieces at least once per week (matched odds ratio $1.41 ; 95 \%$ CI 1.12 , 1.77) and a preference for chicken liver at least once per month (matched odds ratio $2.31 ; 95 \%$ CI $1.29,4.16)$.

There was an inverse association for above average consumption of most salads and other raw vegetables in a typical month. Preferences for salads made at home, including lettuce salads, coleslaw, and potato salads all seemed to be protective against disease. A similar effect was seen with raw vegetables eaten at least three times per week (matched odds ratio 0.69; $95 \%$ CI $0.53,0.92)$. No associations were found for meat or seafood salads, or for fruit salads. Prepackaged salads eaten at least once per week were positively associated with disease (matched odds ratio $2.10,95 \%$ CI $1.25,3.52)$.

Few food preparation practices in the home were associated with disease, including how poultry and other meats were handled. Use of the same chopping board to cut raw meat or poultry and to prepare other foods had no association with disease, although using a chopping board made of wood seemed to be protective against disease (matched odds ratio $0.77 ; 95 \%$ CI $0.61,0.96)$. Chopping board cleaning practices had no association with disease.

Results of the multivariate analysis are shown in table 5, together with population attributable risk percentages. The strongest population attributable risk percentage was derived from not consuming any chicken that was baked or roasted in the previous 10 days. Preference for chicken pieces, consumption of undercooked chicken or other meats and fish in the prior 10 days, and consumption of chicken in a sit-down restaurant also had large population attributable risk percentages.

\section{Discussion}

POULTRY

Previous studies have frequently shown associations between campylobacteriosis and the consumption of poultry. In some studies only raw or undercooked poultry was associated with disease. ${ }^{59}$ In others there was a link with both fully cooked chicken and raw or undercooked chicken. ${ }^{6} 8$

This study confirmed a leading role for poultry in human campylobacter infections. The combined population attributable risk percentage for the chicken related variables in the multivariate model exceeded $50 \%$, suggesting that consumption of chicken lies behind more cases of campylobacteriosis in New Zealand than all other risk factors combined.

Microbiological surveys of processed chicken ready for sale in New Zealand and elsewhere support the biological plausibility of this finding. A microbiological survey of 164 raw poultry samples, collected at random in 1992-93 from registered New Zealand poultry processors, found that 84 samples $(51 \%)$ were contaminated with campylobacter. ${ }^{16}$ This rate was comparable to those reported in the United States, ${ }^{17}$ and the United Kingdom. ${ }^{18}$

The raised risk associated with chicken consumption in our study was dependent on the cooking method, which may be related to the thoroughness of cooking. Baking or roasting chicken may ensure that campylobacter contamination has been eliminated prior eating. Barbecued or fried chicken, on the other hand, may not be thoroughly cooked on the inside. Freezing chicken may also reduce risk. This finding was consistent with the New Zealand microbiological survey, which found that none of 17 frozen chickens studied had any campylobacter present. ${ }^{16}$

Increased risk from chicken meals eaten outside the home has been shown elsewhere. Cooking of chicken in commercial establishments may be less thorough than necessary, in the interest of serving large numbers of patrons as rapidly as possible. The finding that risk is higher from sit-down restaurants than takeaway establishments is interesting, and requires further study.

If chicken has played a role in the growing incidence of campylobacteriosis in New Zealand, possible reasons may include a growing preference for chicken among consumers or a wider availability of the types of chicken servings having higher risks. It is also possible that campylobacter contamination of raw poultry products for sale in New Zealand has increased or that preferred cooking methods of 
chicken in homes and restaurants have changed.

\section{OTHER FOOD FACTORS}

Preferences for meats other than poultry showed almost no associations with campylobacteriosis. This finding parallels those found elsewhere, ${ }^{6-8}$ and suggests that preventive efforts be targeted particularly at poultry.

The strong protective effects of salads and vegetables, other than meat salads, fruit salads, and prepackaged salads, could have occurred because people who bother to prepare salads with their meals may be more careful to ensure that their meats, including poultry, are cooked thoroughly. These may also be chance findings resulting from multiple comparisons, and should be confirmed in other studies.

The absence of links between food preparation practices in the home and campylobacteriosis has also been observed in Norway. ${ }^{7}$ This suggests that while good hygiene in the kitchen is important, it is the thorough cooking of foods, particularly poultry, that may be most essential in preventing disease. The apparent protective effect of using chopping boards made of wood has been discussed elsewhere, ${ }^{19}$ but should be accepted cautiously.

\section{NON-FOOD RISK FACTORS}

Overseas travel is widely accepted as a risk factor for campylobacteriosis and other enteric infections. ${ }^{14}$ The association with rainwater as a home water source has not been described elsewhere, but it is biologically plausible. These water systems are typically untreated. Wild birds, which are a major animal reservoir for Campylobacter species, can easily contaminate these systems by roosting on the roof where the rainwater is collected.

Contact in the home with puppies has also been linked to campylobacteriosis in Britain. ${ }^{12}$ Dogs are known to have a high rate of carriage of campylobacter, ${ }^{20}$ and the playful disposition of puppies no doubt facilitates transmission. Increased risk of campylobacteriosis following contact with a diarrhoeic pet has been seen previously. ${ }^{13}$ The occupational risk of campylobacteriosis from handling meat carcasses has been noted already in New Zealand. ${ }^{21}$

\section{POTENTIAL SOURCES OF BIAS}

Care was taken to ensure that systematic differences in case patients and controls were minimal. Once it was known that a matching control resided at a particular address, that residence was called repeatedly to recruit the matching individual into the study. Despite such safeguards it is possible that the controls who ended up in the study were simply more likely than case patients to spend time at home. If so, this could explain some or all of the risk seen with exposures to foods prepared outside of the home. There was also a danger from selecting controls by telephone, as occasionally the information obtained about who lived in a household may have been false.

Further bias may have been introduced if case patients remembered details of their exposures better than controls because of their illness. We sought to balance the superior recall of case patients by asking controls to recall their exposures, including food consumption, from a more recent reference period, the 10 days prior to the interview. This technique has been used elsewhere. ${ }^{8}$

\section{CONCLUSION}

Campylobacteriosis is a common disease with a number of common causes, the most important being consumption of undercooked chicken. Awareness of thorough cooking can be achieved through public health messages promoting the baking and roasting, instead of the frying and barbecuing, of chicken. Restaurants may need special targeting to ensure that the chicken they serve is cooked sufficiently.

Most of the other risk factors for this disease are also modifiable by simple behavioural changes. These would include avoidance of unpasteurised dairy products and untreated drinking water. Other preventive measures would include careful hand washing after handling animal carcasses, live cattle or calves, and puppies.

We thank Michele Bandaranayake, Steve Bell, Diana Benfell, Mel Brieseman, Lester Calder, Bruce Cameron, Stephen Colombus, Ruth Coombes, Rose Curry, Kirsten Dacre, Nigel Dickson, John Dockerty, Allan Galloway, Jan Gilby, Maureen Gillon, Jackie Hartley, Sally Hasell, Tim Haynes, Rowena Hunt, Dave Jack, Vance Kerslake, Katie Longmuir, Mary-Anne Mace, Dave Jack, Vance Kerslake, Katie Longmuir, Mary-Anne Mace,
Anne McNicholas, Scott Metcalfe, Anton Mischewski, Peter Mitchell, Jenny Neele, Carolyn Nicol, Lionel Ng, Geoff Mitchell, Jenny Neele, Carolyn Nicol, Lionel Ng, Geof O'Brien, Peg Odams, Jane O'Hallahan, Charlotte Paul, Anne
Perry, Katrina Sharples, Gretchen Smythe, Maora Sweeney, Perry, Katrina Sharples, Gretchen Smythe, Maora Sweeney, Michelle Van Dyke, Donna Warren, Alicia Webb, Jackie Wright and all the medical practitioners in New Zealand who reported cases of campylobacteriosis during the study.

Funding: the New Zealand Ministry of Health and the Public Health Commission.

Conflicts of interest: none.

1 ESR:Health Communicable Disease Centre. New Zealand Public Health Report 1996;3:14-15.

2 ESR:Health Communicable Disease Centre. Communicable Diseases in New Zealand, 1992. Communicable Disease New Zealand 1993;93(Suppl 1):12.

3 Skirrow MB. Campylobacter. Lancet 1990;336:921-3.

4 Lane L, Baker M. Are we experiencing an epidemic of campylobacter infection? Communicable Disease New Zealand 1993;93:57-63.

5 Ikram R, Chambers S, Mitchell P, Brieseman MA, Ikram $\mathrm{OH}$. A case control study to determine risk factors for campylobacter infection in Christchurch in the summer of 1992-3. NZ Med f 1994;107:430-2.

6 Deming MS, Tauxe RV, Blake PA, Dixon SE, Fowler BS Jones TS, et al. Campylobacter enteritis at a university: transmission from eating chicken and from cats. $A m \mathcal{F} E p i$ demiol 1987;26:526-34.

7 Kapperud G, Skjerve E, Bean N, Ostroff S, Lassen J. Risk factors for sporadic campylobacter infections: results of a case-control study in southeastern Norway. $\mathcal{F}$ Clin Microbio 1992;30:3117-21.

8 Harris NV, Weiss NS, Nolan CM. The role of poultry and meats in the etiology of Campylobacter jejuni/coli enteritis. Am f Public Health 1986;76:407-11.

9 Hopkins RS, Olmsted R, Istre GR. Endemic Campylobacter jejuni infection in Colorado: identified risk factors. $A m \mathcal{F}$ Public Health 1984;74:249-50.

10 Schmid GP, Schaefer RE, Plikaytis BD, et al. A one-year study of endemic campylobacteriosis in a midwestern city: association with consumption of raw milk. F Infect Dis 1987; 156:218-22.

11 Wood RC, MacDonald KL, Osterholm MT. Campylobacter enteritis outbreaks associated with drinking raw milk during youth activities: 10 -year review of outbreaks in the during youth activities: a 10-year review of

12 Salfield NJ, Pugh E. Campylobacter enteritis in young children living in households with puppies. $B M F$ 1987;294:21 2 .

13 Saeed AM, Harris NV, DiGiacomo RF. The role of exposure to animals in the etiology of Campylobacter jejun coli enteritis. Am $\mathcal{F}$ Epidemiol 1993;137:108-14.

14 Pearson AD, Healing TD. The surveillance and control of campylobacter infection. Commun Dis Rep 1992;2(12): R133-9. 
15 Southern JP, Smith RMM, Palmer SR. Bird attack on milk bottles: possible mode of transmission of Campylobacter jejuni to man. Lancet 1990;336:1425-7.

16 Gilbert S. Campylobacter and salmonella contamination of poultry. Communicable Disease New Zealand 1993;93:63-6. 7 Blaser MJ, Taylor DN, Feldman RA. Epidemiology of Camylobacter jejuni infections. Epidemiol Rev 1983;5:157-75.

18 Hood AM, Person AD, Shahamat M. The extent of surface contamination of retail chickens with Campylobacter jejun serogroups. Epidemiol Infect 1988;100:17-25.
19 Ak NO, Cliver DO, Kaspar CW. Cutting boards of plastic and wood contaminated experimentally with bacteria. $\mathcal{F}$ Food Protect 1994;57:16-22.

20 Baxter DN. The deleterious effects of dogs on human health: 3. Miscellaneous problems and a control programme. Commun Med 1984;6:198-203.

21 Brieseman MA. The epidemiology of campylobacter infections in Christchurch, 1981-83. NZ Med F 1985;98 391-3. 